\title{
Why do accident and emergency doctors request $\mathrm{X}$-rays?
}

\author{
R. A. WARREN AND D. G. FERGUSON \\ Department of Accident and Emergency Medicine, Royal Hallamshire Hospital, \\ Sheffield
}

\section{ABSTRACT}

A prospective study was carried out to analyse all $\mathrm{X}$-rays requested from the three accident and emergency departments in Sheffield during one week. There were 3253 patients examined, of which $1028(31.6 \%)$ were $\mathrm{X}$-rayed, 1251 sets of $\mathrm{X}$-rays being performed. Few X-rays (4.5\%) were requested for medico-legal reasons.

Skull X-rays were studied in particular detail. Only $5(4.5 \%)$ of 112 films were subsequently reported as abnormal by the radiologist.

The accident and emergency doctor's ability to predict X-ray outcome was not very good, their false positive rate being high at $21 \%$ while their false negative rate was low at $5.5 \%$. This indicates that the accident and emergency doctors tended to be over cautious to compensate for their lack of experience.

\section{INTRODUCTION}

In 1982 an attempt was made to identify potential savings for the Health Service in Sheffield. The high number of X-ray requests from accident and emergency departments seemed to be a potential source of such savings. 'Out of hours' X-rays, that is those requested at night and at weekends were considered especially wasteful. It was mooted that accident and emergency departments were extravagant in ordering X-rays and requested a large number for non-clinical reasons, such as patient expectation or fear of litigation, rather than using the $\mathrm{X}$-ray as a proper adjunct to clinical diagnosis. It was also suggested that even clinically essential $X$-ray requests were of dubious value if, due to his inexperience, the accident and emergency doctor was not able to interpret them correctly. The economics, clinical value and medico-legal aspects of $\mathrm{X}$-rays requested from accident and emergency departments have long been a source of controversy (Raison, 1976; De Lacey, 1976) and many attempts at analysis and laying down policy guidelines have been given (Bell \& Loop, 1971; De Lacey et al., 1979a, 1979b, 1980). This study aimed to provide an analysis by accident and emergency

Correspondence: $M r R$. A. Warren, Department of Accident and Emergency Medicine, Royal Hallamshire Hospital, Glossop Road, Sheffield, S10 2fF 
specialists who see the problems from a different standpoint than other specialist involved with emergency X-rays.

All three accident and emergency departments in Sheffield agreed to participate The Royal Hallamshire Hospital (RHH) (adults only); the Sheffield Children's Hospita $\overrightarrow{\overrightarrow{\underline{B}}}$ (SCH) (children only) and the Northern General Hospital (NGH) (adults and children).

\section{METHODS}

All three accident and emergency departments in Sheffield were studied for a one-week period from 9.00 am Monday until 9.00 am the following Monday in the autumn of 1982. During the study a proforma (Table 1 ) was attached to every X-ray request card 3 . The completed proforma was compared to the radiologist's report, which was accepted as the final arbiter. The radiologist was a Consultant or Senior Registrar in the majority of cases.

Strict anonymity of accident and emergency medical staff was observed in the hope of reducing any modifying effect on usual practice which the study might induce on theses doctors.

Table 1

\section{X-RAY STUDY}

Patient:

-RHH

Hospital -NGH Number

$-\mathrm{SCH}$

Grade of Requesting Doctor:

\section{Consultant}

Associate Specialist

Clinical Assistant

Senior Registrar

Registrar

SHO

Pre-Reg HO

Date of X-Ray Request:

(PLEASE STATE

Time of Request:

$\mathrm{am} / \mathrm{pm}$

View requested

What is your PRIME reason for requesting X-ray?

-Suspected fracture or dislocation

- Suspected foreign body

- Specific request from GP

- Specific request from patient or relative

- Possible child abuse

-Medico-legal

-Other

(PLEASE STATEP

At the Time of Request, what is your index of suspicion?

a Positive outcome-STRONG likelihood

b Positive outcome-SLIGHT but DEFINITE likelihood

c Negative outcome-highly likely 
Table 1-continued

On Viewing the X-Ray:

a Positive finding

(PLEASE TICK)

b Negative finding

c Unsure of interpretation-need senior or specialist help

d Incidental finding of medical significance

\section{RESULTS}

As can be seen from Table 4, the most common individual request was for a chest X-ray $(11.8 \%$ of all requests). The most common reason given for $\mathrm{X}$-raying the chest was infection at all ages, and in the investigation of chest pain, cardiac failure and chronic respiratory disease in the middle aged and elderly.

Skull X-rays were the fourth most commonly requested film, comprising $8.9 \%$ of requests. At the $\mathrm{SCH}$ the skull $\mathrm{X}$-ray was the commonest film requested.

Taking 'normal working hours' as $9.00 \mathrm{am}-5.00 \mathrm{pm}$ Monday-Friday and $9.00 \mathrm{am}-1.00 \mathrm{pm}$ on Saturday, then the greater proportion of X-ray requests were made within this period 632 or $50.5 \%$. Out of hours $520(41.6 \%)$ were requested and in 99 $(7.9 \%)$ no time was entered on the proforma. This is equivalent to an ' $\mathrm{X}$-ray request per hour' rate of 14.4 in the normal working day as opposed to 4.2 out of hours.

Table 2 Patients attending and number of X-rays

\begin{tabular}{lcllc}
\hline & RHH & NGH & SCH & Total \\
\hline New patients & 986 & 620 & 526 & 2132 \\
Return visits & 500 & 241 & 380 & 1121 \\
Total attendances & 1486 & 861 & 906 & 3253 \\
New patients X-rayed & $528(53 \cdot 5 \%)$ & $253(40 \cdot 8 \%)$ & $164(31 \cdot 2 \%)$ & $945(44 \cdot 3 \%)$ \\
Return patients X-rayed & $32(6 \cdot 4 \%)$ & $19(7 \cdot 9 \%)$ & $19(5 \cdot 0 \%)$ & $70(6 \cdot 2 \%)$ \\
Not known & 5 & 3 & 5 & 13 \\
Total patients X-rayed & $565(38 \%)$ & $275(31 \cdot 9 \%)$ & $188(20 \cdot 8 \%)$ & $1028(31 \cdot 6 \%)$ \\
Total films requested & 714 & 321 & 216 & 1251 \\
\hline
\end{tabular}

Table 3 Doctor's grade compared to positive 'pick-up' rate

\begin{tabular}{lcr}
\hline Doctor's grade & $\begin{array}{c}\text { No. of X-rays } \\
\text { requested }\end{array}$ & No. positive \\
\hline Consultant & $12(1 \%)$ & $4(33 \cdot 5 \%)$ \\
Associate specialist & $2(0 \cdot 2 \%)$ & 0 \\
Clinical assistant & $130(10 \cdot 4 \%)$ & $33(25 \cdot 4 \%)$ \\
Senior registrar & $13(1 \%)$ & $5(38 \cdot 5 \%)$ \\
Registrar & $44(3.5 \%)$ & $11(25 \cdot 0 \%)$ \\
SHO & $669(53 \cdot 5 \%)$ & $178(26 \cdot 6 \%)$ \\
Pre-reg HO & $381(30 \cdot 5 \%)$ & $51(13 \cdot 4 \%)$ \\
Total & $1251(100 \%)$ & \\
\hline
\end{tabular}


146 R. A. Warren and D. G. Ferguson

Table 4 Breakdown of individual X-ray requests

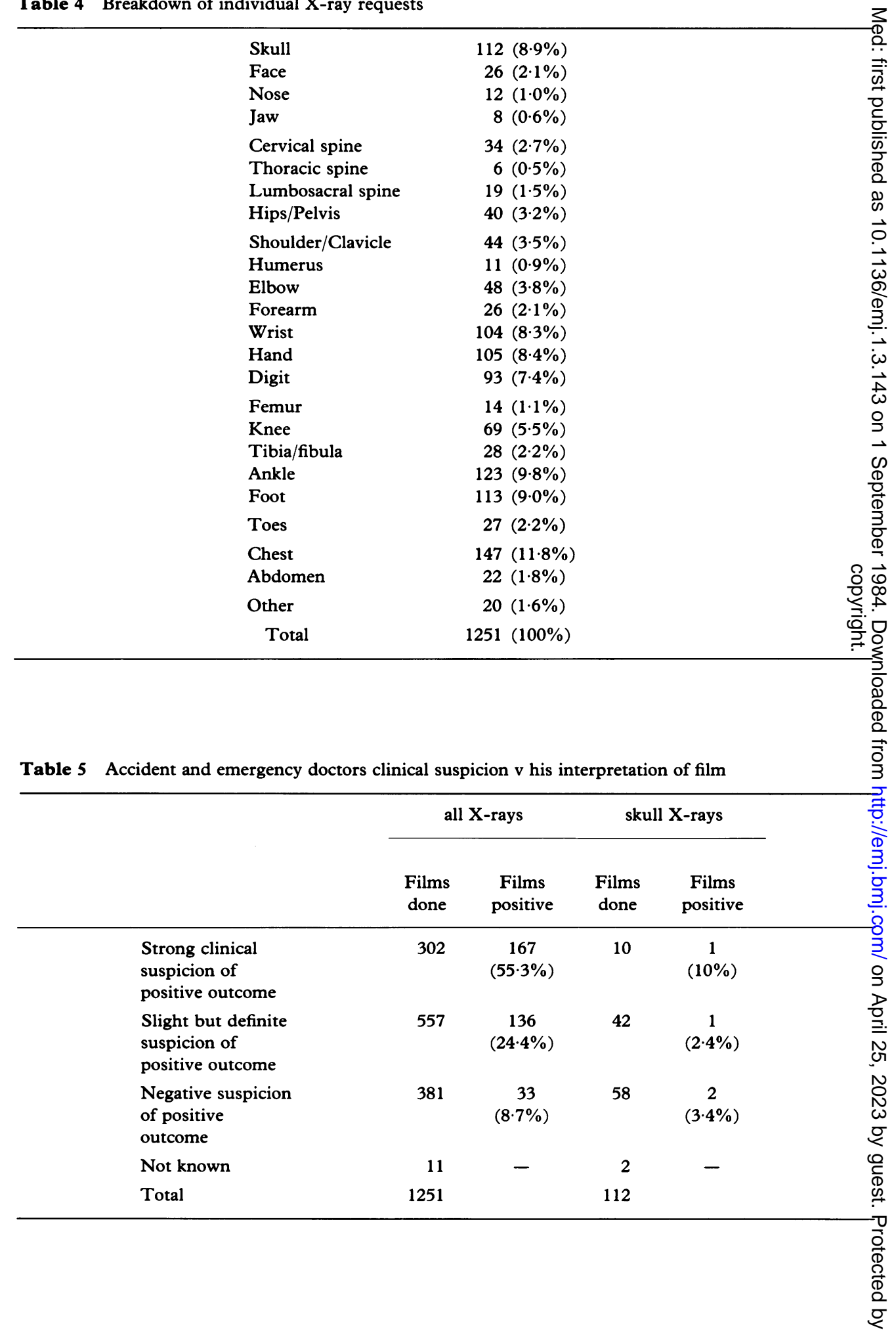


Table 6 Accident and emergency doctor's interpretation compared to radiologist's report

\begin{tabular}{|c|c|c|c|c|c|c|}
\hline & $\begin{array}{l}\text { Radiologist's } \\
\text { report } \\
\text { positive }\end{array}$ & $\begin{array}{l}\text { Radiologist's } \\
\text { report } \\
\text { negative }\end{array}$ & $\begin{array}{l}\text { Radiologist's } \\
\text { report } \\
\text { equivocal }\end{array}$ & $\begin{array}{l}\text { Radiologist } \\
\text { reports } \\
\text { incidental } \\
\text { finding }\end{array}$ & $\begin{array}{c}\text { Not } \\
\text { known }\end{array}$ & Total \\
\hline $\begin{array}{l}\text { Doctor's } \\
\text { interpretation } \\
\text { positive }\end{array}$ & $\begin{array}{c}209 \\
(63 \cdot 3 \%)\end{array}$ & $\begin{array}{c}86 \\
(26 \cdot 1 \%)\end{array}$ & $\begin{array}{c}13 \\
(3.9 \%)\end{array}$ & $\begin{array}{c}3 \\
(0.9 \%)\end{array}$ & $\begin{array}{c}19 \\
(5 \cdot 8 \%)\end{array}$ & $\begin{array}{c}330 \\
(100 \%)\end{array}$ \\
\hline $\begin{array}{l}\text { Doctor's } \\
\text { interpretation } \\
\text { negative }\end{array}$ & $\begin{array}{c}42 \\
(5 \cdot 5 \%)\end{array}$ & $\begin{array}{c}665 \\
(86 \cdot 7 \%)\end{array}$ & $\begin{array}{c}24 \\
(3 \cdot 1 \%)\end{array}$ & $\begin{array}{c}12 \\
(1.6 \%)\end{array}$ & $\begin{array}{c}24 \\
(3 \cdot 1 \%)\end{array}$ & $\begin{array}{c}767 \\
(100 \%)\end{array}$ \\
\hline $\begin{array}{l}\text { Doctor unsure } \\
\text { of interpretation }\end{array}$ & 16 & 62 & 5 & 5 & 8 & 96 \\
\hline $\begin{array}{l}\text { Doctor finds } \\
\text { incidental } \\
\text { finding }\end{array}$ & - & 4 & - & 1 & 1 & 6 \\
\hline $\begin{array}{l}\text { Doctor's } \\
\text { interpretation } \\
\text { not known }\end{array}$ & 10 & 36 & - & - & 6 & 52 \\
\hline $\begin{array}{l}\text { Doctor's } \\
\text { interpretation } \\
\text { positive }\end{array}$ & $\begin{array}{c}4 \\
(27 \%)\end{array}$ & $\begin{array}{c}5 \\
(46 \%)\end{array}$ & - & - & $\begin{array}{c}2 \\
(27 \%)\end{array}$ & $\begin{array}{c}11 \\
(100 \%)\end{array}$ \\
\hline $\begin{array}{l}\text { Doctor's } \\
\text { interpretation } \\
\text { negative }\end{array}$ & $\begin{array}{c}1 \\
(1 \cdot 1 \%)\end{array}$ & $\begin{array}{c}79 \\
(90 \cdot 8 \%)\end{array}$ & - & - & $\begin{array}{c}7 \\
(8 \%)\end{array}$ & $\begin{array}{c}87 \\
(100 \%)\end{array}$ \\
\hline $\begin{array}{l}\text { Doctor } \\
\text { unsure of } \\
\text { interpretation }\end{array}$ & - & 2 & - & - & 1 & 3 \\
\hline $\begin{array}{l}\text { Doctor finds } \\
\text { incidental } \\
\text { finding }\end{array}$ & - & 1 & - & - & - & 1 \\
\hline $\begin{array}{l}\text { Doctor's } \\
\text { interpretation } \\
\text { unknown }\end{array}$ & - & 8 & - & 1 & 1 & 10 \\
\hline
\end{tabular}

Table 7 Main reason for X-ray request

\begin{tabular}{lcc} 
& All X-rays & \multicolumn{1}{l}{ Skull X-rays } \\
\hline Suspected fracture or dislocation & $877(70 \cdot 1 \%)$ & $79(70 \cdot 5 \%)$ \\
Suspected foreign body & $78(6 \cdot 2 \%)$ & $2(1 \cdot 8 \%)$ \\
Specific request from GP & $44(3 \cdot 5 \%)$ & $6(5 \cdot 4 \%)$ \\
Specific request from patient or relative & $21(1 \cdot 7 \%)$ & $2(1 \cdot 8 \%)$ \\
Possible child abuse & $2(0 \cdot 2 \%)$ & $2(1 \cdot 8 \%)$ \\
Medico-legal & $56(4 \cdot 5 \%)$ & $18(16 \cdot 1 \%)$ \\
Other clinical reason & $122(9 \cdot 8 \%)$ & $3(2 \cdot 7 \%)$ \\
Not known & $51(4 \cdot 1 \%)$ & - \\
Total & $1251(100 \%)$ & $112(100 \%)$ \\
\hline
\end{tabular}




\section{DISCUSSION}

If only first time attenders are considered a greater proportion were $\mathrm{X}$-rayed at the RHH than the other hospitals (Table 2). During the study the RHH was one of the fevt hospitals in England still employing pre-registration house officers in its accident an emergency department. If they and their X-rays were excluded, the figures would b similar to those from the NGH, where no pre-registration staff were employed.

In this study only $1 \%$ of $\mathrm{X}$-rays were requested by consultants and $1 \%$ by seniow registrars. These low figures are misleading, as these senior doctors are consulted abou many more films even though they may not have requested them personally. Because of these low numbers it is impossible to state whether or not consultants and seniom registrars are more efficient X-ray users. What can be seen from Table 3 is that th\& proportion of positive X-rays produced by SHOs, registrars and clinical assistants is almost identical, while pre-registration house officers fare only half as well. This provides further evidence that accident and emergency departments require morE senior medical staff than inexperienced juniors for both patient safety and efficiencye Few X-rays were requested for non-clinical medico-legal reasons, only $4.5 \%$ overalt (Table 7). This is in contrast to the figure of $10 \%$ obtained by De Lacey et al. (1979a and to studies showing much higher figures of up to $44 \%$ (Evans, 1977). When th accident and emergency doctors were questioned on completion of the study transpired they were not making such requests to prevent themselves being sued for negligence but to aid their patient in any subsequent claim for industrial or crimiga compensation. Interestingly, Pilling (1976) states that after a twenty-year search he wast unable to find any case where failure to request an X-ray was established as the basis a finding of negligence.

The authors did not attempt to determine the effect of the X-ray on clinica management. While this is certainly important (De Lacey et al., 1979b) the place of certain X-rays in clinical management, notably skull X-rays, is controversial (Evans 1977; Mendelow et al., 1983). The work of the Glasgow neurosurgical school is ver娄 influential and holds that a normal or abnormal skull X-ray is of prime importance following head injury (Mendelow et al., 1982, 1983). This inevitably leads to a low yield of abnormal films, $4.5 \%$ in this study, and yields as low as $0.7 \%$ have been reporte $\$$ (Gibson, 1983). On questioning after the study, the doctors said that they X-rayed the skull even though they thought the outcome would be normal in over half $(51.8 \%)$, as t? miss a positive finding, even though unlikely, might have catastrophic consequences fo the patient. Similarly, it is important to appreciate that the absence of a fracture on $\mathrm{X}_{0}^{\mathrm{S}}$ ray may be a positive finding and help in sending a patient home. The use of $\mathrm{X}$-rays in this way is not confined to unusual injuries. If ten old ladies who had fallen clinically had hip fracture, but only four showed fractures on X-ray, the efficiency of X-ray usag would not be $40 \%$, it would be $100 \%$.

The accident and emergency doctor's clinical suspicion at the time of making the $\mathrm{X}_{\mathscr{N}}^{N}$ ray request is revealing. In those cases when he was strongly suspicious of a positive outcome to the X-ray, he found such a feature in little more than half $(55.3 \%)$. This shows that the accident and emergency doctor is not very good at relating his clinicaf impression with the subsequent X-ray finding, as has been shown before (De Lacey $e e_{4}$ al., 1980). However, the figures imply that the accident and emergency doctors are 
aware of their shortcomings, which is why they tend to overestimate the likelihood of a positive outcome i.e. opt on the 'safe side'.

In $381(30.5 \%)$ of cases the accident and emergency doctor thought that the film would be negative at the time of making the request, and he was right in $91.3 \%$. While in some circumstances a negative $\mathrm{X}$-ray is of crucial significance, the actual number requested in one week is disturbing. Even more disturbing is that $8.7 \%$ of these anticipated normal X-rays showed a positive feature. It would appear that the X-ray is used to a certain extent as a 'safety net', picking up cases that the accident and emergency doctor has himself missed.

The philosophy of 'opt on the safe side' is once more displayed when the accident and emergency doctor's X-ray interpretation is compared to the radiologist's report. Eighty-six $(26 \cdot 1 \%)$ of 330 films thought abnormal by the accident and emergency doctors were normal, and $42(5.5 \%)$ of 767 films thought normal by accident and emergency doctors were abnormal. This is also worrying and may have serious consequences (De Lacey et al., 1980).

In conclusion the Sheffield study shows three things. Firstly, that accident and emergency doctors, particularly when inexperienced, are not wholly accurate in predicting and interpreting emergency radiographs; secondly, that these doctors err very much on the side of caution; thirdly, that few $\mathrm{X}$-rays are requested for non-clinical medico-legal reasons. Continued teaching and ready advice is essential from the growing number of trained accident and emergency specialists, so that the 'safety net' alluded to previously may be pitched at a more reasonable level.

\section{ACKNOWLEDGEMENTS}

Our sincere thanks are due to Dr C. M. Illingworth and Mrs K. M. Taylor (Consultants in Accident and Emergency Medicine) and Dr N. A. Barrington, Dr R. K. Levick and Dr M. Collins (Consultant Radiologists) for their help and constructive criticism at every stage in this study.

\section{REFERENCES}

Bell R. S. \& Loop J. W. (1971) The utility and futility of radiographic skull examination for trauma. New England fournal of Medicine 284, 5, 236-9.

De Lacey G. (1976) Clinical and economic aspects of the use of X-rays in the accident and emergency department. Proceedings of the Royal Society of Medicine 69, 758-9.

De Lacey G., Barker A., Wignall B., Reidy J. \& Harper J. (1979a) Reasons for requesting radiographs in an accident and emergency department. British Medical fournal 1, 1595-7.

De Lacey G. \& Bradbrooke S. (1979b) Rationalising requests for X-ray examination of acute ankle injuries. British Medical fournal 1, 1597-8.

De Lacey G., Barker A., Harper J. \& Wignall B. (1980) An assessment of the clinical effects of reporting accident and emergency radiographs. British fournal of Radiology 53, 304-9.

Evans K. T. (1977) The radiologist's dilemma. British fournal of Radiology 50, 299-301.

Gibson T. C. (1983) Skull X-rays in minor head injury. Scottish Medical fournal 28, 132-7. 
Mendelow A. D., Campbell D. A., Jeffrey R. R., Miller J. D., Hessett C., Bryden J. \& Jennett B. (1982 Admission after mild head injury: benefits and costs. British Medical fournal 285, 1530-2.

Mendelow A. D., Teasdale G., Jennett B., Bryden J., Hessett C. \& Murray G. (1983) Risks of intracraniå. haematoma in head injured patients. British Medical fournal 287, 1173-6. haematoma in head injured patients. British Medical fournal 287, 1173-6.
Pilling H. H. (1976) A coroner's view of routine radiology. Proceedings of the Royal Society of Medicine $6 \frac{\sqrt{7}}{3}$
760-2.

Raison J. C. A. (1976) Radiological resources. Proceedings of the Royal Society of Medicine 69, 755-6.

Received 14 February 1984; editorial comments to authors 19 March 1984; accepted for publication 16 April 198 出 